\title{
In defense of a broad conception of experimental philosophy ${ }^{1}$
}

[forthcoming in Metaphilosophy]

David Rose ${ }^{2}$

Rutgers University

David Danks ${ }^{3}$

Carnegie Mellon University

\footnotetext{
${ }^{1}$ We would like to thank Eric Schwitzgebel and an anonymous referee for helpful comments on an earlier version of this paper. David Danks was partially supported by a James S. McDonnell Foundation Scholar Award.

${ }^{2}$ Department of Philosophy

1 Seminary Place

New Brunswick, NJ 08901

david.rose@ rutgers.edu

${ }^{3}$ Department of Philosophy

135 Baker Hall

Pittsburgh, PA 15231
} 
Experimental philosophy is often held out as a new movement that avoids many of the difficulties that face traditional philosophy. We distinguish two views of experimental philosophy-a narrow view in which philosophers conduct empirical investigations of intuitions and a broad view which says that experimental philosophy is just the co-location in the same body of (i) philosophical naturalism and (ii) the actual practice of cognitive science. These two positions are rarely clearly distinguished in the literature about experimental philosophy, both pro and con. We argue first that the broader view is the only plausible one; discussions of experimental philosophy should recognize that the narrow view is a caricature of experimental philosophy as it is currently done. We then show both how objections to experimental philosophy are transformed and how positive recommendations can be provided by adopting our broad conception of experimental philosophy.

Keywords: experimental philosophy; narrow conception; broad conception; cognitive science; philosophical naturalism 
Much has been made about experimental philosophy as a new movement, paradigm, or methodology for philosophy. There has been discussion about what it all means, how things are different as a result of this new movement, and what distinctive, novel challenges arise from it. We present reasons for thinking that many of these debates are founded on a false premise - namely, that experimental philosophy is something novel and different. As a result, our understanding of the import, benefits, and shortcomings of recent work has suffered.

On our view, there is little that is intellectually novel about experimental philosophy, though we readily grant that there is some sociological novelty (e.g., tenure-stream jobs now being advertised explicitly for "experimental philosophers"). But even this is not unprecedented. Experimental philosophy should not be understood as a novel, intellectual revolution in philosophy. Rather, experimental philosophy should be understood as simply the co-location in the same body of (i) philosophical naturalism; and (ii) standard, everyday cognitive science. If our view about experimental philosophy is correct, then many debates that are currently framed at the level of the movement (e.g., "what is the philosophical relevance of facts about people's intuitions?’) are debates that turn on philosophical naturalism. And many debates about specific experiments are, given a background agreement on philosophical naturalism, essentially questions about cognitive science (e.g., "how do we best experimentally measure the relevant intuitions?"). These observations lead to some positive recommendations for the actual practice of experimental philosophy. We begin with the issue of what “experimental philosophy” is.

\section{Experimental Philosophy: Broadly Construed}

Experimental philosophy is often held out as though it is a revolution in philosophy, or that it somehow avoids many of the challenges that face traditional philosophy. The very framing of issues in terms of "traditional vs. experimental philosophy" - exemplified by, e.g., the burning armchair as a logo for some experimental philosophers - implies that this enterprise is both crucially different in some way 
from previous philosophy and an improvement upon other ways of doing philosophy. Knobe \& Nichols (2008) refer to the "new movement of experimental philosophy" (p. 3); Nahmias, et al. (2005) talk about "the nascent field of "experimental philosophy"” (p. 123); even a relative critic of experimental philosophy such as Sosa (2007) discusses "how it [experimental philosophy] might amount to something novel and promising" (p. 99).

There is clearly something sociologically different going on here: namely, the systematic and widespread co-location in specific individuals of both philosophizing and psychological experimentation. As a historical matter, there simply have not tended to be significant numbers of people doing both philosophy and cognitive science. At the same time, it is important to recognize that such co-location is far from unprecedented. To give just one example of many, ${ }^{4}$ Helmholtz's experiments on perception that culminated in his 1910 three-volume Treatise on Physiological Optics were explicitly intended to test many of Kant's claims about the nature and origin of the categories; ultimately, in Helmholtz's view, they refuted many (though not all) of those claims. Presumably, however, the novelty of experimental philosophy is not supposed to be due solely to sociological factors.

Part of the problem is that discussions of experimental philosophy have often been ambiguous about what exactly experimental philosophy is. For example, Knobe \& Nichols, in the introduction to their 2008 volume, propose that "experimental philosophers [are those who] proceed by conducting experimental investigations of the psychological processes underlying people's intuitions about central philosophical issues" (p. 3). Similarly, Nadelhoffer \& Nahmias (2007) write: "Experimental philosophy is...a recent movement whose participants use the methods of experimental psychology to probe the way people make judgments [i.e., have intuitions] that bear on debates in philosophy." (p. 123) Liao, Weigmann, Alexander, \& Vong (2011) observe that "a number of philosophers have conducted empirical studies that

\footnotetext{
${ }^{4}$ Piaget and Kohlberg also provide excellent historical examples of people engaged in both philosophizing and psychological experimentation. Thanks to Eric Schwitzgebel for bringing the Piaget reference to our attention.
} 
survey people's intuitions about various subject matters in philosophy" (p. 2), and describe their own work as using "this method of experimental philosophy" (p. 2). These quotes and other writings suggest a narrow conception of experimental philosophy: experimental philosophy involves philosophers conducting psychological experiments for which the primary target is intuitions or judgments. This narrow conception is also, we suggest, a common view (though not the only one) in the public informal debate within the philosophical community about the importance of experimental philosophy.

Here are three reasons why the narrow conception should be resisted. First, it is based on a seemingly arbitrary disciplinary chauvinism, as it includes only those individuals who are (or are viewed as) professional philosophers. This restriction leads to some bizarre conclusions, such as that, in the many collaborations involving philosophers and psychologists (e.g., Schwitzgebel \& Cushman, 2012 Young, Nichols, \& Saxe, 2010), only the philosophers get to count as experimental philosophers. ${ }^{5}$ Second, the narrow conception restricts experimental philosophy to the study of folk intuitions. Paradigmatic instances of experimental philosophy (e.g., Machery, et al., 2004) do concern the measurement, analysis, and explanation of intuitions, but there is no clear reason to focus on intuitions to the exclusion of other types of philosophically relevant cognitive data. Consider, for example, recent experimental work on cognitive representations of causal structure in the world, some of it by philosophers or in collaboration with them (e.g., Bonawitz, et al., 2010; Danks, 2007; Glymour, 1998; Gopnik, et al., 2004). This research is clearly philosophically relevant (as used in, e.g., Campbell, 2010; Danks, 2005, 2009; Glymour \& Danks, 2007; Newsome, 2003; Woodward, 2007), but it does not qualify on the narrow conception as experimental philosophy, simply because it aims to understand the representations underlying various explanations and actions, rather than intuitions about when the word 'cause' can be used. Third, and perhaps most importantly, the narrow conception of experimental philosophy should be resisted because it does not seem to capture much of the actual practice. For example, some of the explicit "definitions" of

\footnotetext{
${ }^{5}$ Interestingly and anecdotally, we have found multiple non-philosophers who do in fact balk at describing themselves as experimental philosophers, even though we would argue that their work should be understood in this manner. It is unclear whether this hesitation is for intellectual or professional reasons, however.
} 
experimental philosophy clearly take a broader view of experimental philosophy. ${ }^{6}$ Thus, although the quotes provided earlier (and other discussions) sometimes suggest the narrow conception, both proponents and opponents should not understand experimental philosophy in this way.

We should instead adopt a broad conception of experimental philosophy: experimental philosophy is simply an instantiation of the long tradition of philosophical naturalism - the view that empirical data are relevant to certain philosophical questions - coupled with actually conducting some of the relevant experiments, as necessary. ${ }^{7}$ We believe that both conditions are necessary in characterizing experimental philosophy and experimental philosophers. Naturalists such as Jerry Fodor or Philip Kitcher would not be considered experimental philosophers on the broad conception, nor should they be, as neither actually conducts experiments. Similarly, someone who uses neuroscientific data in philosophical debates about the nature of color (e.g., Matthen, 1999) would not count as an experimental philosopher, unless he or she actually conducted the experiments. A distinction is sometimes drawn between 'experimental philosophy' and 'empirical philosophy' (e.g., Prinz, 2008)—sometimes called ‘empirically-informed philosophy'— where the latter refers to philosophical work that uses various empirical results, particularly from the cognitive sciences, in philosophical theorizing. We agree that there is a distinction here, but suggest that it is actually a subset relation: the former is a subset of the latter. 'Empirical philosophy' is essentially just another term for philosophical naturalism, usually of a rather broad sort; the broad conception of 'experimental philosophy' is empirical philosophy that involves experiments that happen to have been done by the same individual (or more broadly, by members of some collaborative group).

\footnotetext{
${ }^{6}$ E.g., at the Experimental Philosophy Society website. We thank an anonymous reviewer for drawing our attention to this.

${ }^{7}$ We focus on cognitive science in characterizing our broad conception of experimental philosophy, since the most controversy has arisen about psychological experiments that purport to bear on substantive philosophical issues. Our conception of experimental philosophy could be applied more broadly, however, to include "experimental philosophy of biology", "experimental philosophy of physics", or even, as Eric Schwitzgebel has pointed out to us, his recent experimental work on the external world as a form of "experimental philosophy of cosmology".
} 
One notable difference between the narrow and broad conceptions is that the latter focuses on practice, rather than the individual or her training. For example, many psychologists are, on the broad conception, also experimental philosophers. Helmholtz counts as an experimental philosopher, as he sought to use his empirical results to draw philosophical conclusions. Additionally, linguistic, anthropological, and even certain types of biological research can all count as experimental philosophy, provided that the empirical data is being used to draw substantive philosophical conclusions and the researcher is engaging in the actual practice of cognitive science. For example, many of the investigations - both pro and con — of the Whorf-Sapir hypothesis that language deeply shapes cognition would plausibly fall under this broad conception of experimental philosophy.

There are at least two natural concerns that rise in connection with the broad conception. The first is that it strains the use of language to say that psychologists, for example, can be experimental philosophers. Perhaps this paves the way for a reductio of the broad conception: the broad conception implies Helmholtz was an experimental philosopher; Helmholtz clearly was not an experimental philosopher (he was a psychologist!); therefore, the broad conception cannot be correct. We think this reaction is based, however, on a misunderstanding: our position is that the philosophy in 'experimental philosophy' is really philosophical naturalism, which is simply a commitment to look to empirical facts to draw substantive philosophical conclusions. Moreover, this entire line of thought begs the question: the reductio "objection" presupposes that Helmholtz was not an experimental philosopher, but the proper understanding of that term is exactly what is at issue.

The second concern is that the broad conception is too inclusive, as one might worry that all scientists are naturalists, and so experimental philosophers. ${ }^{8}$ This concern, however, is based on a misunderstanding of philosophical naturalism. Philosophical naturalism is not simply the view that any data is relevant to philosophical issues. Rather, it is the stronger claim that some data matter because they

\footnotetext{
${ }^{8}$ Thanks to Eric Schwitzgebel for emphasizing this worrisome possibility.
} 
bear on substantive philosophical issues. In contrast, the research of many scientists does not bear directly on philosophical questions (or at least, not in a significant way). That is, many scientists are not philosophical naturalists in their research. Though the broad conception is more inclusive than the narrow conception, it is not so inclusive as to imply that any experimentalist is necessarily an experimental philosopher. We revisit this issue in Section 3.

For reasons of space, we will not argue directly for the idea that experimental philosophers are doing cognitive science, as there seems to be little controversy about this claim. Experimental philosophers are engaged in the empirical investigation of the nature of human cognition, which clearly fits under the heading of 'cognitive science.' We focus instead on experimental philosophy as "just" part of the long tradition of philosophical naturalism. By the term 'naturalism,' we mean the philosophical commitment that particular types of empirical facts, as determined by one or another science, are relevant to particular philosophical questions or problems. That is, we take naturalism to be the position that philosophy cannot be done solely by linguistic analysis or a priori reasoning, but rather requires the incorporation of certain types of empirical facts (Kitcher, 1992).

According to this formulation, philosophical naturalism is a graded notion-there are degrees of naturalism - and the extent of one's philosophical naturalism can vary across philosophical domains. In epistemology, for example, one might have a relatively minimal naturalism in which empirical facts matter only for determining whether humans have the capacity to meet certain independently established normative standards, or one could have a quite strong naturalism in which much of "standard analytic epistemology" is to be replaced by an epistemology fully grounded in psychological facts (e.g., Bishop \& Trout, 2005). In metaphysics, one might hold that the empirical sciences provide only broad constraints, or move towards the idea that some metaphysical questions can be fruitfully informed or perhaps even wholly answered by the sciences (Goldman, 2007; Jackson, 1998; Ladyman and Ross, 2010; Paul, 2010. Moreover, one need not have the same degree of naturalism in all domains. Many die-hard naturalists 
about epistemology, for example, would nonetheless balk at any significant naturalism about logic. One can hold that many areas of philosophy should be relatively continuous with the sciences, without being committed to the obviously false claim that all philosophical questions are just empirical ones (Kitcher, 2011).

The naturalism in experimental philosophy should be as clear as the cognitive science. Experimental philosophers run experiments precisely because they believe that the resulting data are informative about philosophical questions. For example, experimental philosophers working on the nature of actual causation in human experiences rely on, and actually run, experiments that elicit judgments of actual causation in a range of situations (e.g., Alicke, Rose, \& Bloom, 2011; Hitchcock \& Knobe, 2009). The resulting empirical facts are relevant to core philosophical questions only if one is a suitable naturalist about those questions. Or consider the fact that, in many areas of philosophical discourse, arguments for position $X$ over position $Y$ are grounded in claims that a relevant ordinary concept more closely accords with $X$. For example, Nahmias, Morris, Nadelhoffer, \& Turner (2006) noted that a common claim in debates about free will (e.g., Kane, 1999; Strawson, 1986) is that our ordinary concept of free will includes the view that we cannot be morally responsible if our actions are wholly causally determined by factors outside of our control, and so alternative views of freedom are at an argumentative disadvantage. Nahmias, et al. reveal their naturalism by holding that the claim about our ordinary concept should be subject to empirical data and testing; that is, psychological experimentation is required to properly establish this claim. Nahmias, et al. also engage in the actual practice of cognitive science: they run psychological experiments to test the relevant empirical claims for this instance of philosophical theorizing. They thus provide an excellent example of the broad conception of experimental philosophy.

The broad conception suggests that there is no particular experimental philosophy "movement," since there are as many varieties of experimental philosophy as there are varieties of naturalism. There is thus little point in debating its merits or deficiencies as a unitary whole. Rather, we should focus on particular 
studies, proposals, or uses of empirical data, as there is simply too much variability to draw conclusions about all experimental philosophy (see also Sommers, 2011). Some might be good and some might be bad, but that must be determined on a case-by-case basis, either by challenging the actual cognitive science or the appropriateness of the degree of naturalism that is motivating the empirical work. At the same time, experimental philosophy on the broad conception is not simply psychology, as suggested by Kauppinen (2007, 2011). There are interesting and distinctive metaphilosophical questions about its practice, implications, and viability. Experimental philosophy aspires to be the justified importation of psychological methods and data to answer philosophically significant questions, but this is a non-trivial task. To the extent that either naturalism is inappropriate for some particular philosophical questions or the methods of the cognitive sciences are used poorly, experimental philosophy will appear to be nonviable. But neither of these observations precludes the possibility of informative and valuable instances of experimental philosophy, broadly construed.

\section{Reconsidering the arguments around experimental philosophy}

The considerations in the previous section do not concern some idle terminological or definitional dispute. Rather, an (implicit and incorrect) focus on the narrow conception by some authors has led to a variety of misguided arguments about experimental philosophy. We focus here on how these discussions change if we understand experimental philosophy as the conjunction of naturalism and running the actual experiments. On the proponents' side, any purported advantages of experimental philosophy must arise not because of something novel in this enterprise, but rather because (a) naturalism might sometimes be a more appropriate way to address certain philosophical questions in certain domains, or (b) engaging in the actual practice of cognitive science is the appropriate way to gather the relevant empirical facts for the philosophical question(s) at issue. At the same time, on the opponents' side, criticisms about the supposed limitations of experimental philosophy are actually more specific concerns about either naturalism or the 
specific tools and methods deployed in the actual cognitive science done by experimental philosophers. Objections to experimental philosophy (rather than arguments in its favor) have consumed more of the metaphilosophical literature about experimental philosophy, and so we focus on them in this section. Space constraints (and presumably, reader patience) preclude an exhaustive consideration of all objections ever presented, so we focus on the major classes of objections and concerns about experimental philosophy. Importantly, we are not claiming in this section that all experimental philosophy is good or immune to objections; bad science or inappropriate naturalism can and should be rejected. Rather, our goal in this section is to show the misguided nature of many arguments that purport to show the inappropriateness of experimental philosophy writ large.

Most such arguments about experimental philosophy center on intuitions: whose intuitions are relevant to the philosophical debate at issue, and how those intuitions should bear on the philosophical debate at issue. Experimental philosophers typically argue that folk intuitions are deeply relevant to certain philosophical debates, while defenders of "traditional" philosophy typically suggest that such intuitions have relatively little philosophical value. We suggest, however, that the issue is more complicated, as the philosophical usefulness of empirical data about intuitions depends on both the appropriateness of naturalism in that context and also what the cognitive science actually tells us.

A standard practice when engaging in conceptual analysis is for the philosopher to use her own intuitions to clarify and elucidate our ordinary concept of $X$ (e.g., Jackson, 1998; Lewis, 1986). Sometimes philosophers are explicit about trying to capture the folk concept of $X$, while other times they are subtler. Experimental philosophers interpret these claims as empirical claims about what ordinary people would say under certain conditions, and their naturalism implies that those claims should actually be tested rather than resting solely on a philosopher's assertion. Ordinary intuitions for a wide range of concepts have been tested, including 'intentional action' (e.g., Knobe, 2004, 2006; Nadelhoffer, 2004; Petit \& Knobe, 2009); ‘causation’ (e.g., Alicke, Rose, \& Bloom, 2011; Hitchcock \& Knobe, 2009; 
Knobe, 2010; Sytsma, Livengood, \& Rose, 2012); 'knowledge' (e.g., Beebee \& Buckwalter, 2010; Swain, Alexander, \& Weinberg, 2008; Turri, 2013; Weinberg, Nichols, \& Stich, 2001); and 'free will' (e.g., Nahmias, et al., 2006; Nichols, 2004). In other cases, we are interested more generally in the cognitive processes that underwrite various intuitions (Machery \& Rose, forthcoming), and so must move beyond simply trying to figure out what the relevant intuitions are.

A common taxonomy (Alexander, Mallon, \& Weinberg, 2010; Nadelhoffer \& Nahmias, 2007) of empirical results about cognitive processes is that they can be used to establish either positive or negative conclusions about the reliability of those intuitions. Machery and Rose (forthcoming), for example, write: revisionists do not challenge the use of intuitions in philosophy, but hold that experimental methods can make philosophers' use of intuitions more reliable; eliminativists are skeptical of the role of at least some types of intuitions in philosophy (p. 3). These are also sometimes referred to as the positive and negative projects in experimental philosophy, respectively (Alexander, et al., 2010; Nadelhoffer \& Nahmias, 2007).

In our view, any successful taxonomy of projects must be sensitive to at least two different dimensions of variation. One dimension is the actual cognitive science: does it show that the intuitions are reliably generated in relevant cases, and are there reasons to think that expert intuitions are different from folk intuitions? A second, distinct dimension is the extent of our naturalism: are folk intuitions appropriate for understanding the concept, or only considered, reflective, expert judgments? Of course, these issues do intersect to some degree; if expert and folk intuitions are generated in the same way, then everyone should agree about the value of empirical data, regardless of other views about naturalism. But it is important to keep the philosophical commitments distinct from what the cognitive science turns out to reveal. In the remainder of this section, we aim to show that the major objections to the use of intuitions by experimental philosophers (e.g., Cullen, 2010; Deutsch, 2009; Kauppinen, 2007; Ludwig, 2010; Sosa, 2010; Williamson, 2012) are actually expressions of anti-naturalism, concerns about the 
cognitive science, or both. They thus do not present objections to experimental philosophy as a global enterprise, but rather are challenges to particular instances of the practice.

The first class of objections (e.g., Kauppinen, 2007; Ludwig, 2010) argues that when professional philosophers talk about "intuitions," they are not actually talking about intuitions in the sense of “immediate responses that can be collected via survey." Instead, philosophers engaged in conceptual analysis are (they argue) basing those analyses on the standard usage of the term in the relevant community of reflective, competent language users, rather than immediate, unreflective responses. ${ }^{9}$ As a result, the argument concludes that folk intuitions - the data collected by many experimental philosophers - are irrelevant to philosophical debates, as the word 'intuition' means different things in the two contexts. We are agnostic about whether the critics' understanding of conceptual analysis is correct. For our purposes, the key point is that this set of objections works only if one believes, contrary to our arguments, that experimental philosophy must be restricted to the study of folk intuitions. That is, the objections presuppose that experimental philosophers are committed to a very restricted type of naturalism. There is no particular reason for a broad experimental philosopher to accept this commitment, however. In fact, the broad experimental philosopher would regard this "objection" as an opportunity to engage in more research: namely, descriptive, experimental, and psycholinguistic research in order to determine what those reliable, competent language users would actually reflectively assent to.

A second class of criticisms focuses on whether the cognitive science, including the psychological methods themselves, actually shows what the experimental philosopher takes it to show. A prime example is Cullen (2010), who called into question the reliability of previous empirical results by showing that subtle variations in survey wording can produce dramatic effects on responses. As another

\footnotetext{
${ }^{9}$ Herman Cappelen (2012) has recently argued that philosophers generally do not rely upon intuitions as evidence in their theorizing, though they may slip up from time to time with talk of "intuitions." Thus, experimental philosophy fails (for Cappelen) to get any traction at all. But this concern threatens only the narrow conception of experimental philosophy, which we argued was already in trouble on independent grounds (see Section 1). The broad conception is unthreatened by Cappelen's position, since it is not restricted to the study of intuitions.
} 
example, Sosa (2010) argued that studies that show cross-cultural variation in the application of the concept 'knowledge' (e.g., Weinberg, Nichols, \& Stich, 2001) can plausibly be explained by the different participants using different sets of facts. Crucially, Sosa's criticism is aimed at the cognitive science; presumably, if improved cognitive science showed that the concept under consideration was genuinely different across cultures, then Sosa would happily concede Weinberg, et al.'s primary point. Similarly, there have been numerous criticisms of Machery, et al.'s (2004) work showing cross-cultural variation in judgments of reference (e.g., Deutsch, 2009; Ludwig, 2007; Marti, 2009; Sytsma \& Livengood, 2011), but the majority of these criticisms have been aimed at the actual cognitive science. Many other examples of objections that are claimed to be about experimental philosophy are actually objections to the specific cognitive science (e.g., DeRose, 2011; Talbot, 2012). These objections are of course important, but the key is that they do not show us anything special with regards to experimental philosophy as an enterprise, as the objectors typically claim. Doing experimental philosophy requires doing cognitive science, as made clear by the broad understanding of it. And part-and-parcel of all normal cognitive science — regardless of whether it is philosophically relevant—is engaging in methodological debates such as these.

Perhaps the most powerful objection to the enterprise of experimental philosophy is the "expertise objection" (Williamson, 2012). The objection suggests that we should not take folk judgments particularly seriously because non-philosophers make errors in their judgments. In contrast, the training of professional philosophers presumably makes them experts in analyzing concepts, making philosophically relevant distinctions, and so forth, and so they are not subject to those same types of errors. Thus, only the judgments of professional philosophers are relevant to certain philosophical disputes.

There are two different ways to understand the expertise objection. One version is based on an antinaturalistic attitude towards epistemology that is grounded in the belief that philosophers have special access to facts about the concept under consideration, and this access serves to stave off empirical facts about the folk usage of that concept. This objection is thus not a challenge to experimental philosophy per 
se, but rather to any naturalistic approach to understanding the nature and content of particular concepts. Moreover, because naturalism is a domain-specific matter, we in fact have a whole class of distinct, specific objections. One could, for example, hold that philosophers have special access to knowledge in one domain (e.g., logic) without thereby being entitled or obligated to conclude that they have such knowledge for all philosophically interesting concepts. Naturalism must be evaluated, whether pro or con, in a more fine-grained way. More practically, the broad conception of experimental philosophy implies that discussions of experimental philosophy must, regardless of conclusion, be clear about the type and extent of naturalism for the philosophical question under consideration. The extent of one's naturalism in a particular domain is crucial to defining dialectical boundaries in debates over the relevance of experimental philosophy.

The second version of the expertise objection focuses instead on the endless practice and experience that philosophers have with intuitions. Such practice has presumably made us experts about our philosophically interesting intuitions, and so ours are the ones that can and should be trusted. Recent work has shown, however, that philosophers' intuitions are not necessarily special: there are significant similarities in philosophers' and non-philosophers' causal judgments (Hitchcock \& Knobe, 2009) and moral judgments (Schwitzgebel \& Cushman, 2012). ${ }^{10}$ The expertise objection also depends on a competence/performance distinction for intuition generation that is left almost completely unspecified in these debates. Most importantly, we contend that this version of the expertise objection is actually a call for more experimental philosophy (broadly construed). A necessary condition for the expertise objection to matter is that the factors that influence the intuitive judgments of non-philosophers be different from those that influence the judgments of professional philosophers. Thus, this version of the expertise objection depends on an empirical demonstration that philosophers' intuitions really are more stable, reliable, etc. than those of the folk. From a cognitive science point-of-view, the best way to answer this

\footnotetext{
${ }^{10}$ There is also some recent empirical evidence suggesting that philosophers are fairly reliable in their empirical speculations about the folk (see Dunway, Edmonds and Manley, forthcoming).
} 
question is to determine the cognitive processes that generate these intuitions, and so determine whether the factors that make a difference are the same in folk and expert populations. We thus have a philosophically important question — do professional philosophers have relevantly superior intuitions?that requires empirical data to answer, and so the expertise "objection" implies that we need more experimental philosophy.

\section{Implications of the broad conception for the practice of experimental philosophy}

If experimental philosophy is understood as philosophical naturalism combined with actually performing the relevant cognitive science, then we can better describe and improve the actual practice and evolution of experimental philosophy. The research that is currently characterized as experimental philosophy is often a survey-driven enterprise: in a typical study, a participant is provided with some hypothetical scenario and asked to decide whether some particular term applies to an event in the story, or whether some relation holds. Some surveys aim to determine the variables that influence responses, but other studies simply poll opinions as if the philosopher worked for Gallup. In either case, this methodology arguably mirrors the practice of actual philosophers engaged in conceptual analysis (Goldman, 2010). The philosopher might not tally up her responses and run statistical tests on the data, but the two methods are strikingly similar.

Verbal responses often provide clear, sufficient evidence about one's immediate intuitions, but sometimes these automatic judgments and our more reflective, considered judgments can come apart. To take one well-known example, Knobe (2004) showed that participants are more likely to judge that a foreseen but unintended side-effect was brought about intentionally when the environment is harmed as opposed to helped. Many explanations have been offered in order to explain these asymmetries in people's judgments of intentional action (e.g., Alicke \& Rose, 2010; Machery, 2008; Sripada, 2009), and 
some strong philosophical conclusions have been drawn from this asymmetry (e.g., Knobe, 2010). In contrast, Pinillos, et al. (2011) recently showed that more reflective subjects (as judged by scores on Cognitive Reflectivity Tests) tend not to show this asymmetry, regardless of professional training. That is, Pinillos, et al. used more sophisticated measures and a different experimental design to perhaps show that a puzzle in intentional action attributions may simply be an artifact of the original study conditions. We thus must be careful about exactly what we take the relevant data to be. More generally, intuitions can arise from both "automatic" and also more "reflective" processes, and different evidential weight is often attached to these "thin" vs. "thick" (respectively) intuitions. ${ }^{11}$ The proper experimental philosophy response to this distinction must ultimately depend on our naturalism and the cognitive science: our naturalism will help determine which types of intuitions are philosophically relevant; the cognitive science guides us to appropriate experimental techniques and methods to explore the underlying cognitive processes that generate both "automatic" and "reflective" judgments.

One such technique is to explicitly model those underlying processes using a formal framework such as structural equation models. Sripada \& Konrath (2011), for example, compare several prominent models of intentional action asymmetries by testing structural equation models that correspond to the different philosophical hypotheses. There are many different causal modeling techniques, and our point is not to engage in debates about which is best (though see, e.g., Rose, Livengood, Sytsma \& Machery, 2012). Rather, the key point is to clearly state and represent cognitive process models so that they can be rigorously tested. Although these techniques have been relatively uncommon to this point in experimental philosophy, there is clearly no principled barrier to using such sophisticated techniques for revealing and understanding the cognitive processes underlying intuitions and behavior.

\footnotetext{
${ }^{11}$ The contrast between "thick" and "thin" intuitions in metaphilosophical discussions of intuitions is principally due to Joshua Alexander and Jonathan Weinberg.
} 
More generally, we wholeheartedly endorse the recent emergence of more sophisticated experimental methodologies, such as reaction time measures. For example, Guglielmo \& Malle have recently (in currently unpublished data) used response reaction times to argue that attributions of intentional action in cases such as Knobe (2004) occur prior to moral judgments, thereby contradicting a common explanation of the asymmetry as arising from moral considerations (e.g., Knobe, 2004; Alicke, 2008). Such methods can also enable us to move beyond measuring and modeling only immediate judgments and intuitions. There are even ways to sometimes get a glimpse at the underlying neuropsychological processes. For example, Greene, et al. (2001) used fMRI techniques to investigate the neuropsychological processes underlying what they call characteristic deontological and characteristic utilitarian judgments in classical trolley cases, finding surprising results. Greene, et al. (2001) suggest, contrary to the standard philosophical view that deontological judgments are "emotion free," that characteristic deontological judgments are affect laden. Our point here is not to endorse the conclusion of Greene and colleagues or suggest that neuroimaging is some sort of universal panacea. Rather, our point is only that more sophisticated experimental techniques can sometimes be useful in uncovering the mechanisms which give rise to certain judgments and that information about underlying mechanisms might sometimes bear on substantive philosophical issues.

Different techniques can often be fruitfully used together to generate philosophically relevant empirical data. Consider, for example, the puzzling cases of moral luck, in which we seemingly want to ascribe blame purely on the basis of a negative, fortuitous outcome (e.g., Nagel, 1972; Williams, 1982). Young, Nichols, \& Saxe (2010) investigated judgments of blame in cases of moral luck using both behavioral and fMRI techniques. They found that, contrary to standard philosophical wisdom, our blame judgments are driven by both negative outcome information and the possession of false beliefs by the agent. A combination of both behavioral and neuropsychological methods can be used to complement each other in the search for uncovering the cognitive processes implicated in various judgments. 
In fact, we argue that even more measures should be used in experimental philosophy, as actions and behaviors can also be deeply philosophically relevant. For example, a recurring theme in (theories of) moral reasoning is a Socratic one: people will behave morally if only they have proper knowledge and understanding of various moral obligations. This idea suggests that moral philosophers should be more likely to behave morally than the general population since they have presumably acquired moral knowledge and understanding through their reflections on moral matters. Schwitzgebel \& Rust (2010) explored this possibility in the domain of voting: in particular, given that there is presumably a (defeasible) moral obligation to vote, do professional political philosophers or ethicists vote more frequently than their peers? Interestingly, Schwitzgebel \& Rust (2010) found no difference in voting behavior between ethicists, political philosophers, other philosophers, or even professors in $\left(\right.$ most $\left.^{12}\right)$ other disciplines. This result suggests that knowledge about moral obligations does not immediately lead to the corresponding, recommended moral behavior, in contrast with the Socratic idea. We present this example not to endorse its conclusion, ${ }^{13}$ but rather to show that measurements of the actual behavior of people can also provide empirical data that is potentially philosophically relevant.

There is a growing trend and increasing recognition among self-identified experimental philosophers that survey-centered methods have significant limitations, and that debates can be fruitfully advanced by using more rigorous methods and by combining various methodological techniques. We believe that this is exactly the right attitude: if an experimental philosopher is to take the cognitive part of the project seriously, then she will need to avail herself of the best experimental methods of cognitive science, including not just survey responses, but also behavioral measures, neuroimaging data, and other measures of cognitive functioning, as well as the best techniques for modeling the data. Of course, complex

\footnotetext{
${ }^{12}$ There was one exception: political scientists had a 10-15\% higher voting rate than other professors.

${ }^{13}$ There are many reasons one might reject their conclusion: voting might not actually be a moral obligation; perhaps the relevant moral knowledge is held by most professors and not just political philosophers and ethicists; there could be other factors that reduce voting rates disproportionately in political philosophers thereby counteracting any "knowledge boost"; and so on. Schwitzgebel and Rust (forthcoming) responds to some of these concerns.
} 
statistical analyses should not replace proper experimental design, but in certain situations, more rigorous statistical analyses can uncover psychologically and philosophically relevant features of the data.

We should emphasize, however, that not all empirical data are philosophically relevant. Another positive recommendation that emerges from the broad conception is actually a caution: one must articulate and defend one's naturalism so that it is clear which empirical data are philosophically relevant, and why they matter for the particular philosophical debates at issue. The relevance of some particular empirical data, whether intuitions or a more sophisticated measure, depends on one's underlying philosophical naturalism. Empirical data matter only to the extent that we have a philosophically sensible justification of the relevance of that data to a philosophical question, issue, or argument. ${ }^{14}$ Some philosophical questions (e.g., Plato's euthyphro question) presumably do not depend in any significant way on cognitive data. At the same time, it is unclear what philosophical debate is impacted by, for example, the demonstration that some people categorize pictures of spiders more slowly when a positive word is simultaneously presented (Ellwart, Rinck, \& Becker, 2006).

More generally, we believe that there is an important opportunity here for experimental philosophy to advance the state of our understanding about naturalism. There have been various explorations of the nature of naturalism (e.g., Kitcher, 1992; Papineau, 1993; Strawson, 1985), and one consistent theme has been the wide varieties of naturalism that are available and defensible, depending on the particular context and question. In many ways, experimental philosophy (broadly construed) provides an exceptional testbed for exploring these different types of naturalism. We must have a clear understanding of the diversity of naturalisms in order to properly understand the relationships between the different available types of empirical data, collected in almost all areas of philosophy, by individuals with diverse views about the proper use of descriptive cognitive data for normative philosophical theories. It is difficult to imagine a

\footnotetext{
${ }^{14}$ Of course, such a justification need not be provided by a philosopher. Psychologists and others are perfectly capable of providing arguments that particular data are relevant.
} 
challenge or problem case for our understanding of philosophical naturalism that does not have some corresponding example in domains investigated by experimental philosophy construed broadly.

\section{Conclusion}

We have argued that many (though not all) discussions concerning the nature of experimental philosophy have explicitly or implicitly used a narrow conception of experimental philosophy that commits one to unjustifiable distinctions - e.g., psychologists cannot be experimental philosophers, or only experiments on intuitions are philosophically relevant—and provides few resources to respond to a range of natural objections. Experimental philosophy should be understood broadly as an instance of a long tradition of philosophical naturalism conjoined with active research in cognitive science. This conception of experimental philosophy best explains much of the actual practice of experimental philosophers, and implies that psychologists can be experimental philosophers; that philosophers can, and often should, do experiments on underlying cognitive processes, representations, and behavior; and that there are many ways to refine and improve the practice.

A focus on the broad conception of experimental philosophy provides a philosophically defensible framework for debates about the movement and its significance for the broader philosophical community. In particular, it implies that such debates should focus on either the philosophical naturalism in some piece of experimental philosophy, or the actual cognitive science that was conducted. Experimental philosophy is not some wholly novel enterprise, but is rather like many other naturalistic approaches to philosophy. The broad conception of experimental philosophy is another way to make philosophy an enterprise that is continuous with some of the sciences (Kitcher, 2011). The commitment to philosophical naturalism and the actual practice of cognitive science has a long history and is not an attack on 
traditional philosophy. Rather, it provides a different set of tools with which to answer the philosophically significant questions that confront us.

At the same time, the broad conception of experimental philosophy is not somehow immune to all challenges; we are not claiming that all experimental philosophy is good philosophy or good experimentation. Rather, we are arguing that the objections to it must be based on concerns about the appropriateness of naturalism in the domain or about the particular cognitive science, rather than broadbased objections to experimental philosophy as a single enterprise. Doing good experimental philosophy (broadly construed) requires stating one's naturalistic commitments, and so acts as a check against the possibility of over-naturalization (though we concede that many experimental philosophers do not do this). And there are certainly plenty of particular experiments in the experimental philosophy literature that are quite problematic, but that is no different from any area of cognitive science. An adoption of the broad conception places experimental philosophy on firmer footing by emphasizing its historical roots in philosophical naturalism and the cognitive sciences. In this way, it situates experimental philosophy within a context where it is a fluid extension of prior practices, which only strengthens the promise and promotion of experimental philosophy as it extends into the future. 


\section{References}

Alexander, J., Mallon, R., \& Weinberg, J. (2010). Accentuate the negative. Review of Philosophy and Psychology.

Alicke, M. (2008). Blaming badly. Journal of Cognition and Culture, 8, 179-186.

Alicke, M., \& Rose, D. (2010). Culpable control or moral concepts? Behavioral and Brain Sciences, 33, $330-331$.

Alicke, M., Rose, D., \& Bloom, D. (2011). Causation, norm violation and culpable control. Journal of Philosophy.

Appiah, A. (2008). Experimental philosophy: 2007 presidential address to the eastern division of the American Philosophical Association. Proceedings and Addresses of the American Philosophical Association, 82.

Bishop, M. A., \& Trout, J. D. (2005). Epistemology and the psychology of human judgment. Oxford: Oxford University Press.

Bonawitz E. B., Ferranti, D., Saxe, R., Gopnik, A., Meltzoff, A. N., Woodward, J., \& Schulz, L.E. (2010). Just do it? Investigating the gap between prediction and action in toddlers' causal inferences. Cognition, 115, 104-117.

Campbell, J. (2010). Control variables and mental causation. Proceedings of the Aristotelian Society, 110, $15-30$.

Cappelen, H. (2012). Philosophy without intuitions. Oxford: Oxford University Press.

Cullen, S. (2010). Survey-driven romanticism. Review of Philosophy and Psychology, 1, 275-296.

Danks, D. (2005). The supposed competition between theories of human causal inference. Philosophical Psychology, 18, 259-272.

Danks, D. (2007). Causal learning from observations and manipulations. In M. C. Lovett \& P. Shah (Eds.), Thinking with data (pp. 359-388). New York: Lawrence Erlbaum Associates. 
Danks, D. (2009). The psychology of causal perception and reasoning. In H. Beebee, C. Hitchcock, \& P. Menzies (Eds.), Oxford handbook of causation (pp. 447-470). Oxford: Oxford University Press.

DeRose, K. (2011). Contextualism, contrastivism and x-phi surveys. Philosophical Studies, 156, 81-110.

Deutsch, M. (2009). Experimental philosophy and the theory of reference. Mind and Language, 24, 445466.

Ellwart, T., Rinck, M., \& Becker, E. S. (2006). From fear to love: Individual differences in implicit spider associations. Emotion, 6, 18-27.

Glymour, C. (1998). Learning causes: Psychological explanations of causal explanation. Minds and Machines, 8, 39-60.

Glymour, C., \& Danks, D. (2007). Reasons as causes in Bayesian epistemology. Journal of Philosophy, 104, 464-474.

Goldman, A. (2007). A program for 'naturalizing' metaphysics, with application to the ontology of events. The Monist, 90, 457-479.

Goldman, A. (2010). Philosophical naturalism and intuitional methodology: Romanell lecture. Proceedings and Addresses of the American Philosophical Association, 115-150.

Gopnik, A., Glymour, C., Sobel, D. M., Schulz, L. E., Kushnir, T., \& Danks, D. (2004). A theory of causal learning in children: Causal maps and Bayes nets. Psychological Review, 111, 3-32.

Greene, J., Sommerville, R. B., Nystrom, L. E., Darley, J. M., \& Cohen, J.D. (2001). An fMRI investigation of emotional engagement in moral judgment. Science, 293, 2105-2108.

Hitchcock, C., \& Knobe, J. (2009). Cause and norm. Journal of Philosophy, 106, 587-612.

Jackson, F. (1998). From metaphysics to ethics: A defense of conceptual analysis. Oxford: Clarendon Press.

Kane, R. (1999). Responsibility, luck, and chance: Reflections on free will and indeterminism. Journal of Philosophy, 96, 217-240.

Kauppinen, A. (2007). The rise and fall of experimental philosophy. Philosophical Explorations, 10, 95118. 
Kauppinen, A. (2011). A modest proposal.

http://experimentalphilosophy.typepad.com/experimental_philosophy/2011/06/a-modest-

proposal.html

Kitcher, P. (1992). The naturalists return. The Philosophical Review, 101, 53-114.

Kitcher, P. (2011). Philosophy inside out. Metaphilosophy, 42, 248-260.

Knobe, J. (2004). Intention, intentional action, and moral considerations. Analysis, 64, 181-187.

Knobe, J. (2006). The concept of intentional action: A case study in the uses of folk psychology. Philosophical Studies, 130, 203-231.

Knobe, J. (2010). Person as scientist, person as moralist. Behavioral and Brain Sciences, 33, 315-329.

Knobe, J. \& Nichols, S. (2008). An experimental philosophy manifesto. In J. Knobe \& S. Nichols (eds.), Experimental philosophy. Oxford: Oxford University Press.

Ladyman, J., \& Ross, D. (2010). Everything Must Go: Metaphysics Naturalized. Oxford University Press.

Lewis, D. (1986). Philosophical papers, Volume II. Oxford: Oxford University Press.

Liao, S. M., Weigmann, A., Alexander, J., \& Vong, G. (2011). Putting the trolley in order: Experimental philosophy and the loop case. Philosophical Psychology, 25(5), 661-671.

Lombrozo, T. (2010). Causal-explanatory pluralism: How intentions, functions, and mechanisms influence causal ascriptions. Cognitive Psychology, 61, 303-332.

Ludwig, K. (2007). The epistemology of thought experiments: First person versus third person approaches. Midwest Studies in Philosophy, 31, 128-159.

Ludwig, K. (2010). Intuitions and relativity. Philosophical Psychology, 23, 427-445.

Machery, E. (2008). Understanding the folk concept of intentional action: Philosophical and experimental issues. Mind and Language, 23, 165-189.

Machery, E., Mallon, R., Nichols, S., \& Stich, S. (2004). Semantics, cross-cultural style. Cognition, 92, B1-B12.

Machery, E., \& Rose, D. (forthcoming). Experimental philosophy. Encyclopedia of the Mind. 
Marti, G. (2009). Against semantic multiculturalism, Analysis, 69, 42-48.

Matthen, M. (1999). The disunity of color. The Philosophical Review, 108, 47-84.

Nadelhoffer, T. (2004). Blame, badness, and intentional action: A reply to Knobe and Mendlow. Journal of Theoretical and Philosophical Psychology, 24, 259-269.

Nadelhoffer, T., \& Nahmias, E. (2007) The past and future of experimental philosophy. Philosophical Explorations, 10, 123-149.

Nagel, T. (1979). Moral luck. In Mortal questions (pp. 24-38), Cambridge: Cambridge University Press.

Nahmias, E., Morris, S., Nadelhoffer, T., \& Turner, J. (2005). Surveying freedom: Folk intuitions about free will and moral responsibility. Philosophical Psychology, 18, 561-584.

Nahmias, E., Morris, S., Nadelhoffer, T., \& Turner, J. (2006). Is incompatibilism intuitive? Philosophy and Phenomenological Research, 73, 28-53.

Nahmias, E., \& Nadelhoffer, T. (2007). The Past and Future of Experimental Philosophy. Philosophical Explorations 10, 2, 123-149.

Newsome, G. L. (2003). The debate between current versions of covariation and mechanism approaches to causal inference. Philosophical Psychology, 16, 87-107.

Nichols, S. (2004). The folk psychology of free will: Fits and starts. Mind and Language, 19, 473-502.

Papineau, D. (1993). Philosophical naturalism. Blackwell Publishers.

Paul, L. A. (2010). New roles for experimental work in metaphysics. European Review of Philosophy and Psychology, 1, 461-476.

Pettit, D. \& Knobe, J. (2009). The pervasive impact of moral judgment. Mind \& Language, 24, 586-604.

Pinillos, N. A., Smith, N., Nair, G. S., Marchetto, P., \& Mun, C. (2011). Philosophy's new challenge:

Experiments and intentional action. Mind \& Language, 26, 115-139.

Prinz, J. (2008). Empirical philosophy and experimental philosophy. In J. Knobe and S. Nichols (Eds.), Experimental Philosophy, Oxford University Press.

Rose, D., Livengood, J., Sytsma, J., \& Machery, E. (2012). Deep trouble for the deep self. Philosophical Psychology, 25, 629-646. 
Schwitzgebel, E., \& Cushman, F. A. (2012). Expertise in moral reasoning? Order effects on moral judgment in professional philosophers and non-philosophers. Mind and Language, 27, 135-153.

Schwitzgebel, E. \& Rust, J. (2010). Do ethicists and political philosophers vote more often than other professors? Review of Philosophy and Psychology, 1, 189-199.

Sommers, T. (2011). In memoriam: The x-phi debate. The Philosopher's Magazine, 52.

Sosa, E. (2007). Experimental philosophy and philosophical intuition. Philosophical Studies, 132, 99-107.

Sosa, E. (2010). Intuitions and meaning divergence. Philosophical Psychology, 23, 419-426.

Sripada, C. (2009). The deep self model and asymmetries in folk judgments of intentional action. Philosophical Studies, 151, 159-176.

Sripada, C. \& Konrath, S. (2011). Telling more than we can know about intentional action. Mind and Language, 26, 353-380.

Strawson, G. (1986). On the inevitability of freedom (from the compatibilist point of view). American Philosophical Quarterly, 23, 393-400.

Strawson, P. F. (1985). Skepticism and naturalism: Some varieties. New York: Columbia University Press.

Swain, S., Alexander, J., \& Weinberg, J. (2008). The instability of philosophical intuitions: Running hot and cold on Truetemp. Philosophy and Phenomenological Research, 76, 138-155.

Sytsma, J., \& Livengood, J. (2011). A new perspective concerning experiments on semantic intuitions. Australasian Journal of Philosophy, 89, 315-335.

Talbot, S. (2012). The irrelevance of folk intuitions to the 'hard problem' of consciousness. Consciousness and Cognition, 21, 644-650.

Weinberg, J., Nichols, S., \& Stich, S. (2001) Normativity \& epistemic intuitions. Philosophical Topics, $29,429-460$.

Williams, B. (1982). Moral luck. In Moral luck (pp. 20-39). Cambridge: Cambridge University Press.

Williamson, T. (2011). Philosophical expertise and the burden of proof. Metaphilosophy, 42, 215-229. 
Woodward, J. (2007). Interventionist theories of causation in psychological perspective. In A. Gopnik \& L. Schulz (eds.), Causal learning: Psychology, philosophy and computation (pp. 19-36). Oxford: Oxford University Press.

Young, L., Nichols, S., \& Saxe, R. (2010). Investigating the neural and cognitive basis of moral luck: It's not what you do but what you know. Review of Philosophy and Psychology, 1, 333-349. 